\title{
Research of ultra-fine bainite X80 pipeline plate for gas compressor station
}

\author{
Shaopo $\mathrm{Li}^{1,2, \mathrm{a}}$, Wenhua Ding ${ }^{1}$ and Hai Zhang ${ }^{1}$ \\ ${ }^{1}$ Shougang Research Institute of Technology; Beijing, 100043, China \\ ${ }^{2}$ Beijing Engineering Research Center of Energy Steel, Beijing, 100043, China
}

\begin{abstract}
This paper reports on the research of low temperature $\left(-51^{\circ} \mathrm{C}\right) \mathrm{X} 80$ pipeline plate used for gas compressor station. In order to satisfy the performance requirements of low temperature X80 pipeline plate, an optimized rolling and cooling process was developed to achieve ultra-fine bainite microstructure and stable mechanical properties. The results showed that by improving the final roughing pass reduction prior to the intermediate holding and the per pass reductions during finish rolling, up to $20 \%$ and $10 \%$ respectively, the austenite grain can be refined and uniformed completely. The optimized cooling process application after finish rolling guarantees the steady control of the final ultra-fine bainite microstructure with optimum M/A phase for X80 plates. The 10000 metric tons plates produced by this process achieved good flatness and excellent low temperature toughness.
\end{abstract}

\section{Introduction}

The development of pipeline steel trends toward higher strength, heavier wall thickness and larger diameters ${ }^{1,2,3}$. Traditional TMCP process can no longer meet the requirements of precise microstructure control, and good flatness utilizing higher cooling rates and lower cooling stop temperatures. This is the driving force that optimized rolling and cooling process was developed in ShouQin Co.Ltd (SQS). Stable mechanical properties of $27.5 \mathrm{~mm} \times 80$, low temperature $\left(-51^{\circ} \mathrm{C}\right)$, large OD (48”) used for pipeline compressor station can be achieved by utilizing this process route.

\section{Optimized Rolling and Cooling Process}

The optimized rolling and cooling process starts from the slab reheating which needs to address both dissolution of the main micro-alloy elements and controlling of the austenite grain coarsening ${ }^{3,4,5}$. The adopted slab reheating temperature in the production to address alloy dissolution and control of austenite grain coarsening was between $1150-1190{ }^{\circ} \mathrm{C}$.

The recrystallized rolling process is the most crucial processing to improve low temperature toughness. For grain refinement it is the most effective metallurgical mechanism able to improve both strength and toughness in high strength pipe steels. The latter passes of the rough rolling stage must be of sufficient deformation (over 15\% per-pass) to achieve good conditioning of the austenite grain through the entire cross section of the plate. And the total reduction must be over 55\% in roughing from the end of the last broadside pass to the final roughing pass, so the prior austenite grain in the slab can be fully recrystallized to as fine as an austenite grain in the $30-50 \mu \mathrm{m}$ range.

Finish rolling of the plates needs to start under the Tnr (non-recrystallized) temperature as determined by the niobium level in the design. Fully recrystallized prior austenite grain will be pancaked/elongated with a total reduction of more than $65 \%$. Deformation under Tnr temperature is quite important for both strength and low temperature toughness 6 . The finish rolling temperature is usually controlled in the range of $50-70{ }^{\circ} \mathrm{C}$ above the Ar3 (phase transformation start temperature).

Post rolling cooling was controlled to achieve the appropriate cooling stop temperature and cooling rate to obtain the ideal microstructure and plate flatness ${ }^{7}$. SQS has two pieces of cooling equipment, one is ACC which was designed by SMS, the other is UFC which has more powerful capability, as Figure 1. The optimized cooling process is based on the combination of two pieces of cooling equipment to achieve a more flexible and optimum cooling condition.

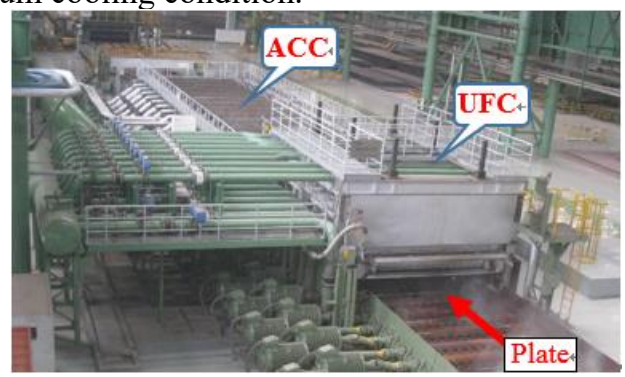

Figure 1. Cooling Equipment of UFC and ACC in SQS

When the finish rolled plate enters the UFC equipment, it will be quickly cooled to the temperature 
of intermediate transformation temperature range with a cooling rate of $30-35^{\circ} \mathrm{C} / \mathrm{s}$ (depending on the actual thickness of plate). And then the plate will be cooled with ACC with a lower cooling rate about $15-20^{\circ} \mathrm{C} / \mathrm{s}$ to the aimed cooling stop temperature. This optimized cooling process enhances the grain refinement after the plate rolling, as shown in Figure 2.

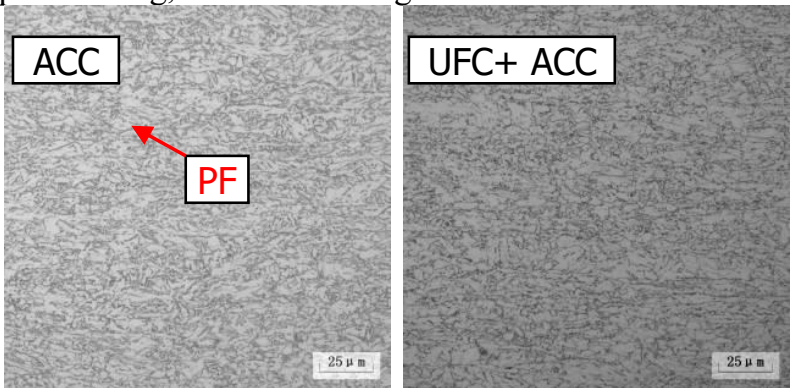

Figure 2. Different Microstructures after ACC and UFC+ACC Processes

Figure 2 shows the differences in microstructures produced by ACC and UFC+ACC process. The microstructures from the ACC process consist primarily of bainite and some polygonal ferrite $(\mathrm{PF})$. While the microstructures from the UFC+ACC process consists of a refined lower bainite and $\mathrm{M} / \mathrm{A}$ constituent. The average grain size of ACC process is coarser than the UFC + ACC grain.

Beside the improvement to the microstructure of plate, optimized cooling process also helps to the plate flatness after powerful cooling. Figure 3 shows when the plate exit the cooling system after UFC+ACC, the flatness is much better than the ACC cooled plate.

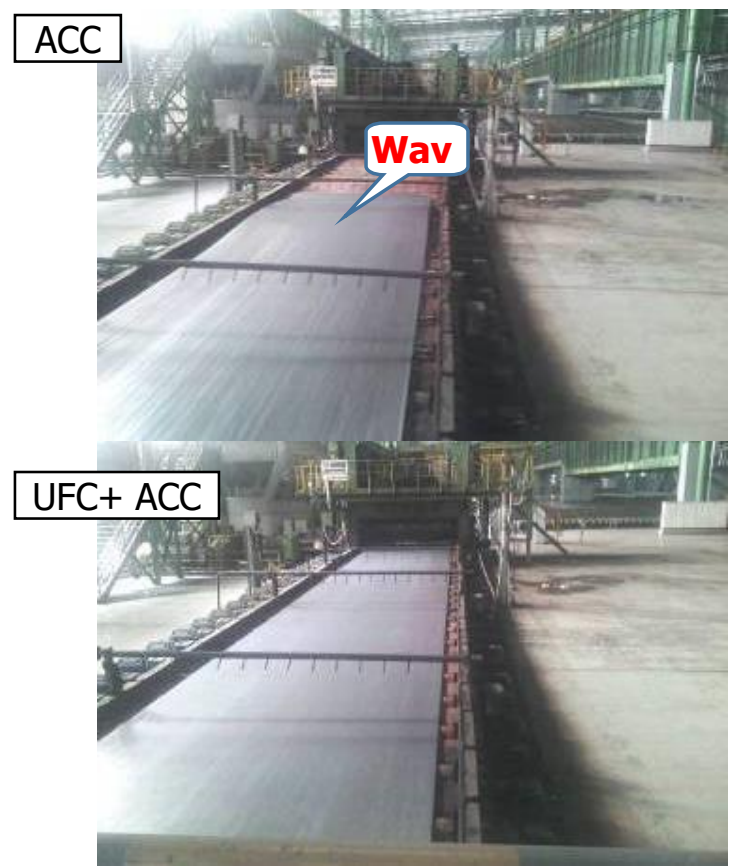

Figure 3. Flatness of Plate after Using Two Different Cooling Processes

\section{Low Temperature X80 Production}

By using the optimized rolling and cooling process mentioned above, SQS has produced 10000 metric tons 27.5mm x $1219 \mathrm{~mm}$ (48”) OD X80 for gas pipeline compressor station.

Table 1 shows the chemistry design for $27.5 \mathrm{~mm}$ X80 pipeline plate of compressor station.

Table 1. Chemistry of $27.5 \mathrm{~mm}$ x $1219 \mathrm{~mm}$ (48") OD X80 Pipeline Steel (wt.\%)

\begin{tabular}{|c|c|c|c|c|}
\hline $\mathrm{C}$ & $\mathrm{Si}$ & $\mathrm{Mn}$ & $\mathrm{Ni}+\mathrm{Cr}+\mathrm{Cu}+\mathrm{Mo}$ & $\mathrm{Nb}+\mathrm{V}+\mathrm{Ti}$ \\
\hline$\leqslant$ & $\leqslant$ & $\leqslant$ & $\leqslant 0.70$ & $\leqslant 0.08$ \\
0.06 & 0.30 & 1.80 & \\
\hline
\end{tabular}

Figure 4 shows the rolling schedule of the $27.5 \mathrm{~mm}$ X80 plate using $400 \mathrm{~mm}$ thickness slab. The total reduction is $64 \%$ in roughing after broadsiding and $69 \%$ in finishing. The final roughing pass reduction prior to the intermediate holding and the per pass reductions during finish rolling, reach up to about $20 \%$ and above $10 \%$ respectively.

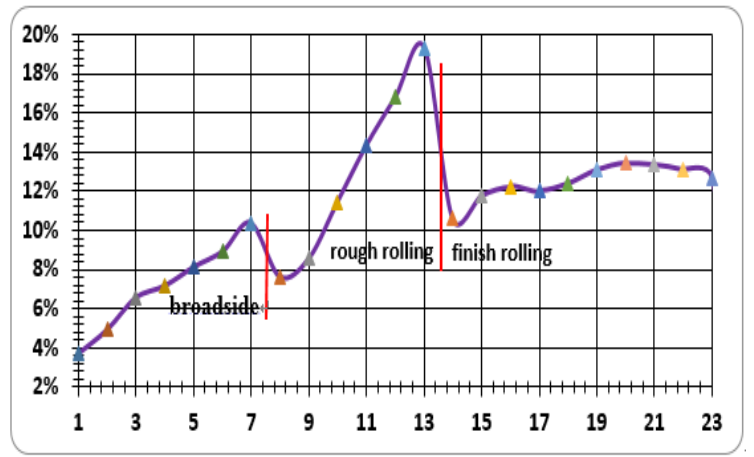

Figure 4. The Rolling Schedule of $27.5 \mathrm{~mm}$ X80 Pipeline Plate

The optimized cooling process application after finish rolling guarantees the steady control of designed microstructure for X80 plates. An ultra-fine bainite microstructure + small M/A constituents was obtained, as shown in Figure 5. The plates possess high strength, low $\mathrm{Y} / \mathrm{T}$ ratio, high toughness at low temperature, good DWTT properties.

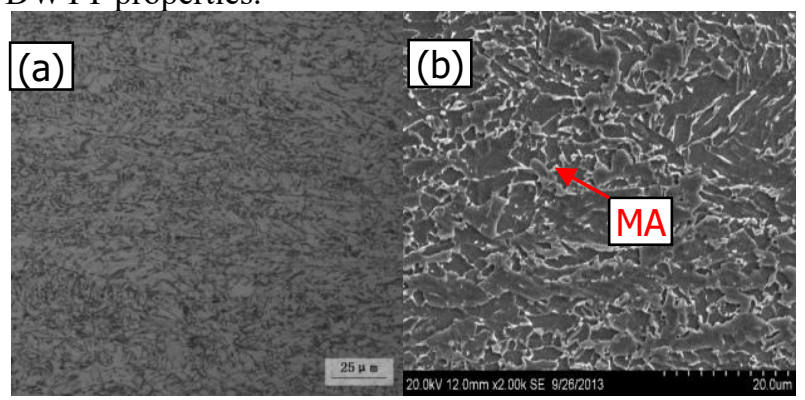

Figure 5. Microstructure of $27.5 \mathrm{~mm}$ X80 Pipeline Plate

Figure 6 shows the transition curve of the plate Charpy impact test. Charpy impact absorbed energy at $51{ }^{\circ} \mathrm{C}$ still on the upper shelf close to $480 \mathrm{~J}$. Figure 7 shows the transition curve of the plate DWTT. The shear area still remains $75 \%$ at $-51{ }^{\circ} \mathrm{C}$ test temperature for full thickness sample. Charpy impact test was done on a 600J machine and DWTT was done on a $50,000 \mathrm{~J}$ machine. 


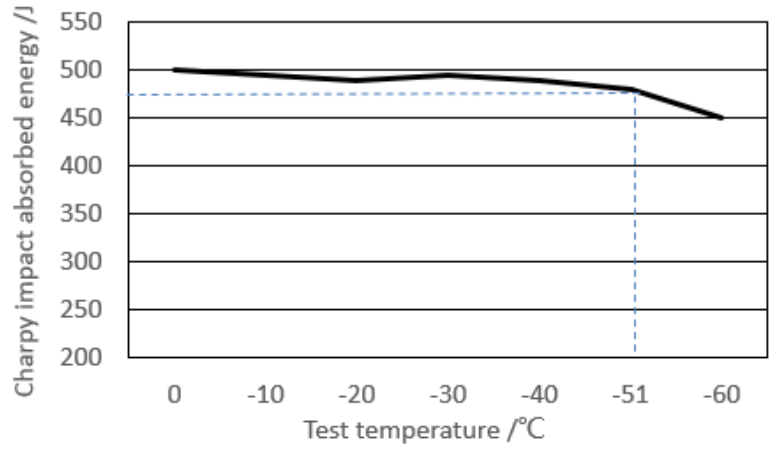

Figure 6. CVN Transition Curve for $27.5 \mathrm{~mm}$ X80 Plate (Transverse Direction, Mean values)

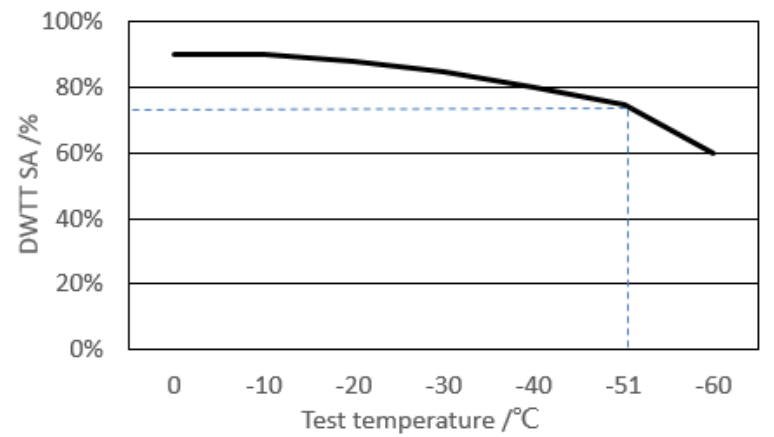

Figure 7. DWTT Transition Curve for $27.5 \mathrm{~mm}$ X80 Plate (Transverse Direction, Full size, Mean values)

\section{Conclusions}

In order to satisfy the requirements of low temperature X80 pipeline plate, an optimized rolling and cooling process was developed. According to the production practice on $27.5 \mathrm{~mm}$ X80 low temperature $\left(-51^{\circ} \mathrm{C}\right)$, large OD (48") plates, the following conclusions can be drawn:

1. A new rolling and cooling process is developed and applied to produce low temperature heavy gauge X80 pipeline plate for gas compressor station. All the plates obtained excellent low temperature toughness.

2. The optimized cooling process application after finish rolling guarantees the steady control of the final ultra-fine bainite microstructure with optimum M/A phase for X80 plates and further more result in the consistent and stable control of mechanical properties of plates.

3. With the improvement of the plate cooling uniformity and microstructure by using optimized rolling and cooling process, a better plate flatness is achieved in production.

\section{References}

1. F. Siciliano, D. Stalheim, J. Gray, "Modern High Strength Steels for Oil and Gas Transmission Pipelines", Proceedings of 7th International Pipeline Conference 2008, IPC2008-64294.

2. W. Li, C. Huo, Q. Ma, et al., "The Development of Large Diameter \& Thickness X80 HASW Linepipe”, Proceedings of 7 th International Pipeline Conference 2008, IPC2008-64500.
3. D. Stalheim, S. Li, W. Ding, Z. Jiang, et al., "Research and Development Into Low Temperature Toughness of Large Diameter Heavy Wall X80 Pipeline Steel at Shougang Steel", Proceedings of 9th International Pipeline Conference 2012, IPC2012-90326.

4. Z. Zhang, Q. Zhang, "Effect of Heating Temperature on Prior Austenite Size and Solution of $\mathrm{Nb}$ in Pipeline Steel", Journal of Iron and Steel Research, 2008(10): 36 39.

5. D. Stalheim, Y. Yin, et al., " Development and Capability of High Temperature Processing (HTP) Pipeline Steel at Nanjing Iron and Steel Company”, Proceedings Pipeline Technology Conference 2009, Ostend Belgium, 2009.

6. D. Stalheim, "Metallurgical Optimization of Microalloyed Steels for Oil and Gas Transmission Pipelines", Proceedings of 6th International Conference on High Strength Low Alloy Steels (HSLA Steels 2011). Beijing China, June 2011.

7. S. Li, Q. Ma et al., "Research of Basic Parameters of Nb-Ni series X70 Pipeline Steel”, [J]. Steel Rolling, 2009, 26(5): 5-8. 